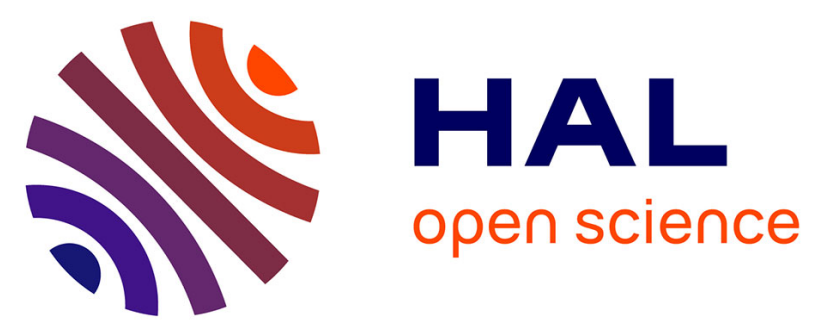

\title{
Amyloid- $\beta$ in Alzheimer's Disease: A Study of Citation Practices of the Amyloid Cascade Hypothesis Between 1992 and 2019
}

Timothy Daly, Marion Houot, Anouk Barberousse, Yves Agid, Stéphane Epelbaum

\section{To cite this version:}

Timothy Daly, Marion Houot, Anouk Barberousse, Yves Agid, Stéphane Epelbaum. Amyloid- $\beta$ in Alzheimer's Disease: A Study of Citation Practices of the Amyloid Cascade Hypothesis Between 1992 and 2019. Journal of Alzheimer's Disease, 2020, 74 (4), pp.1309-1317. 10.3233/JAD-191321 . hal-02989156

\section{HAL Id: hal-02989156 https: / hal.sorbonne-universite.fr/hal-02989156}

Submitted on 5 Nov 2020

HAL is a multi-disciplinary open access archive for the deposit and dissemination of scientific research documents, whether they are published or not. The documents may come from teaching and research institutions in France or abroad, or from public or private research centers.
L'archive ouverte pluridisciplinaire HAL, est destinée au dépôt et à la diffusion de documents scientifiques de niveau recherche, publiés ou non, émanant des établissements d'enseignement et de recherche français ou étrangers, des laboratoires publics ou privés. 


\section{Beta-amyloid in Alzheimer's Disease: A study of citation practices of the amyloid cascade hypothesis between 1992 and 2019}

Timothy Daly¹, Marion Houot²,3, Anouk Barberousse1, Yves Agid², Stéphane Epelbaum²,3

\section{$\underline{\text { ABSTRACT }}$}

The amyloid cascade hypothesis $(\mathrm{ACH})$ has dominated contemporary biomedical research into Alzheimer's disease (AD) since the 1990s but lacks confirmation by successful clinical trials of anti-amyloid medicines in human $\mathrm{AD}$. In this uncertain period regarding the centrality of betaamyloid $(\mathrm{A} \beta)$ in the $\mathrm{AD}$ disease process, and with the community apparently divided about the ACH's validity, we used citation practices as a proxy for measuring how researchers have invested their belief in the hypothesis between 1992 and 2019. We sampled 445 articles citing Hardy \& Higgins ("HH92") and classified the polarity of their HH92 citation according to Greenberg (2009)'s citation taxonomy of positive, neutral, and negative citations, and then tested four hypotheses. We identified two major attitudes towards HH92: a majority $(62.7 \%)$ of neutral attitudes with consistent properties across the time period, and a positive attitude (35.0\%), tending to cite HH92 earlier on within the bibliography as time went by, tending to take HH92 as

\footnotetext{
${ }^{1}$ Philosophy Department, Sorbonne Université, Paris, France.

Mail: Timothy Daly, timothy.daly@paris-sorbonne.fr

2 Centre of excellence of neurodegenerative disease (CoEN), ICM, CIC Neurosciences, APHP Department of Neurology, Pitie-Salpêtriere Hospital, University Paris 6, Paris, France.

3 Department of Neurology, Institute of Memory and Alzheimer's Disease (IM2A), Pitie-Salpêtriere Hospital, APHP, Boulevard de l'hôpital, Paris, France.
} 
an established authority. Despite the majority of neutral HH92 citations, there was a positive majority of attitudes towards newer versions of the $\mathrm{ACH}$ and anti-amyloid therapeutic strategies (67.4\%), suggesting that the $\mathrm{ACH}$ has been dominant and has undergone significant refinement since 1992. Finally, of those 110 original articles within the sample also testing the ACH empirically, an overwhelming majority (89\%) returned a pro-ACH test result, suggesting that the ACH's claim is reproducible. Further studies will quantify the extent to which results from different methods within such original studies convergence to provide a robust conclusion vis-àvis $A \beta$ 's pathogenicity in AD.

\section{$\underline{\text { INTRODUCTION }}$}

There are and have been several aetiological hypotheses of Alzheimer's disease (AD), but the amyloid cascade hypothesis $(\mathrm{ACH})$, which claims that cerebral beta-amyloid deposition is the driving pathogenic factor of $\mathrm{AD}$, has been the most dominant over the last 25 years $[1,2]$. Interestingly, despite the dominance of the $\mathrm{ACH}$, there have been no successful clinical trials with anti-amyloid agents (though see promising results from [3]. The ACH's scientific merit has been drawn into question on multiple occasions [4], and many experts are skeptical, even cynical about the status it has enjoyed[5].

The ACH is a biomedical hypothesis in that its evaluation is both biological and medical. In biology, it must adequately explain the etiology of AD. In medicine, it will be evaluated by its ability to help the development of disease-modifying therapies based on its claims. It is because 
of the dual biomedical nature of the hypothesis that not only its confirmation, but also its refutation, is extremely difficult.

The philosopher Sir Karl Popper (1902-1994), famous amongst contemporary biomedical scientists, proposed that testing hypothetical conjectures was the essential activity of science. Furthermore, he proposed that negative results tell us more about the truth of a hypothesis than confirmatory ones: the accumulation of supposedly confirmatory data can continue ad infinitum, whereas the obtention of a false test result supposedly tells us that something is wrong with the theory now[6].

However, Popper's intuition about falsification can only take us so far, logically speaking. It is extraordinarily difficult with a clinical trial to test the theoretical core of the ACH (that betaamyloid deposition is central to human $\mathrm{AD}$ ) due to the number of "auxiliary hypotheses" or background assumptions involved in the test of any one anti-amyloid agent [7]. In short, the $\mathrm{ACH}$ predicts that an anti-amyloid agent, in patients correctly diagnosed, given at the appropriate stage of the disease, targeting the correct species of beta-amyloid, with the correct targeting mechanism (see debates around passive vs. active immunisation), at the right dose, will have some important disease-modifying effect. It is only when all of these obstacles have been overcome that we can say that the hypothesis is being truly tested by a clinical trial.

Given these difficulties, we reason that studying confirmation and refutation of the ACH cannot be soundly pursued at this stage by a bibliometric study, but have chosen instead to study the beliefs of scientists towards the ACH. In his famous 1877 article[8] "The Fixation of Belief," the scientist-philosopher Charles Sanders Peirce (1839-1914) suggested that there were 4 methods by which we arrive at our beliefs: individual tenacity, collective authority, a priori racionation, 
and science. The scientific method, he claims, is the only method "by which our beliefs may be determined by nothing human, but by some external permanency - by something upon which our thinking has no effect" (CP5.385).

As early as 2001 in AD research, certain researchers have felt that human factors have contributed to the dominance of the ACH: Joseph et al. [9] called this phenomenon "The Church of the Holy Amyloid"; Mudher and Lovestone [10] used religious language to refer to "TAUists" (defending the primacy of tau involvement) and "BAptists" (defenders of the $\mathrm{ACH}$ ) defending the role of these proteins in $\mathrm{AD}$ aetiology.

In light of the difficulties testing the logical confirmation or refutation of the $\mathrm{ACH}$, and the hypothesised existence of divided belief with the possibility of ideology within the AD community, we have chosen to study the acceptance of the $\mathrm{ACH}$ and test certain hypotheses about how it has been accepted, using citations as a proxy for acceptance or refusal of the idea by researchers within the field, as a way of measuring their belief in the ACH's validity. The main question we asked about such practices was, "When the authors of scientific papers cite this paper devoted to explicitly defending the $\mathrm{ACH}$, do they tend to do so in a polarised (positive, neutral, or negative) way?" The methodology used in this study was inspired by Greenberg[11], who likewise used citation practices to measure the "belief in a specific scientific claim by studying the pattern of citations among papers stating it." He found that when the authors of a scientific paper encounter and cite the claim that $\beta$-amyloid is associated positively with inclusion body myositis, he could divide the citation into those receiving the idea positively, neutrally, and negatively. He also discovered that amongst citing articles there was an overwhelming preponderance to cite the idea positively. 
We tested four hypotheses about citation practices of articles citing HH92. Firstly, we wished to test Hardy et al. [1]'s claim of the dominance of the ACH. Secondly, validation of the citation metric: whether HH92 citations could be used to predict how scientists positioned themselves towards the ACH. Thirdly, whether it pays to cite HH92 favourably, leading to higher citation rates of positively-citing articles. Fourthly, whether HH92 was cited earlier within articles with time; for example, as a growing authority on AD.

Finally, recognising the importance of reproducibility of evidence in favour of a hypothesis, as a measure of its scientific support, we measured how many original articles in our sample tested the $\mathrm{ACH}$ and how many arrived at a favourable test result.

Thus, our study classifies citations according to Greenberg's taxonomy, as a measure of how researchers encounter the idea of "Amyloid deposition as the central event in the aetiology of Alzheimer's disease," and tests hypotheses about such practices and their consequences.

\section{$\underline{M E T H O D S}$}

\section{HUB SELECTION AND SAMPLING}

Four candidates for the ACH hub were identified [12-15]. "Alzheimer's Disease: The Amyloid Cascade Hypothesis" ("HH92") was chosen, since firstly, as its title suggests, the claims of the $\mathrm{ACH}$ are most explicitly laid out, and secondly, this article has the most citations within this wave of "pro-ACH" articles [Figure 1]. 


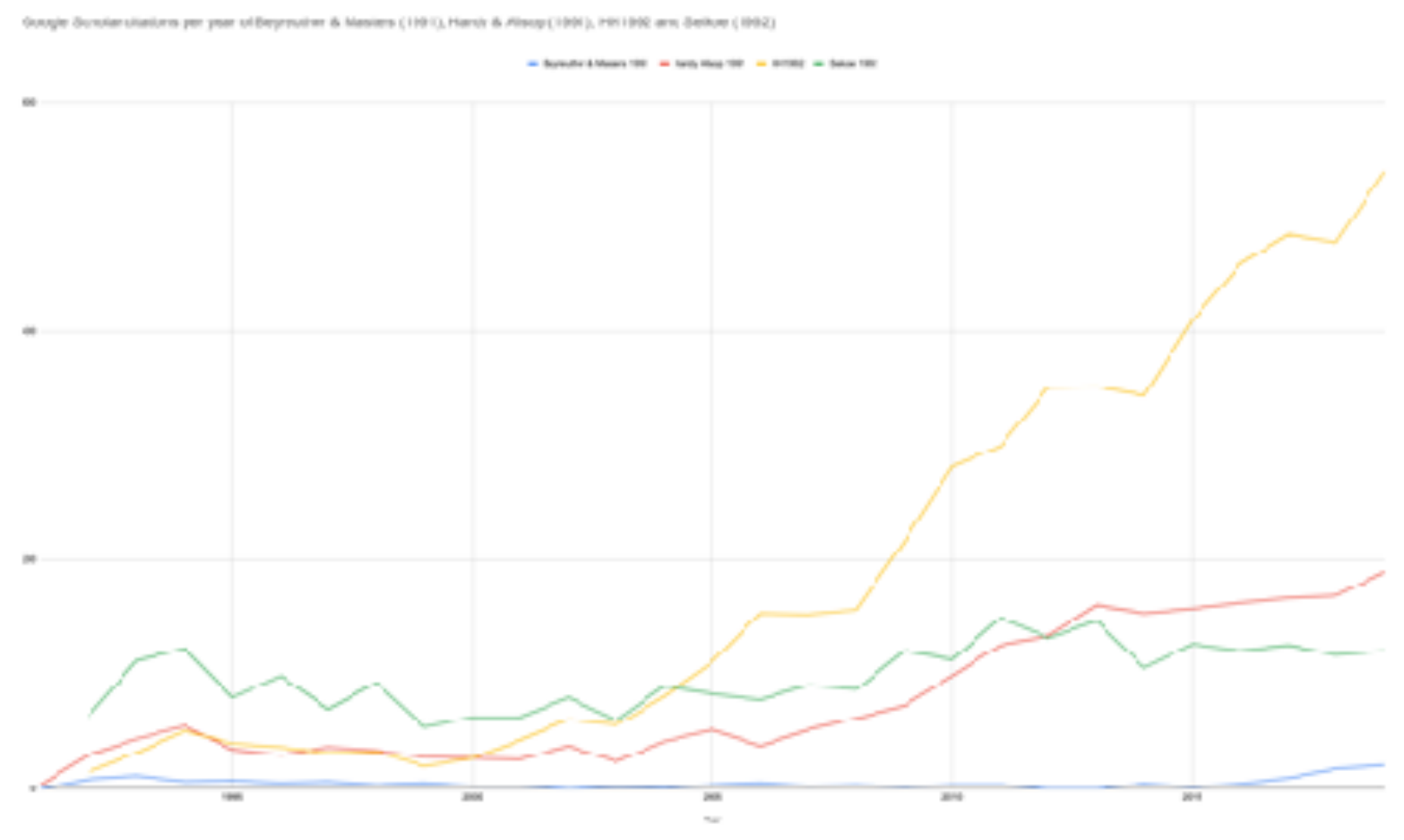

Figure $1-\mathrm{HH} 92$ is the ACH hub most likely to be influencing the beliefs of citing authors due to the explicit nature of its title as a defence of the $\mathrm{ACH}$ and its growing impact in the literature in terms of citations.

A sample of 1 in 10 random articles was chosen (540 / 5400 articles). 95 articles were excluded: those not written in English, not published in peer-reviewed scientific journals, or with 0 citations since their publication (since we wished to measure the transmission of the major idea of the $\mathrm{ACH}$, and an article with 0 citations has no citation-related impact).

\section{DETERMINING HH92 CITATION AND ACH VALENCE}


Inspired by Greenberg's study[11], who "classified each citation as supportive, neutral, or critical according to how its underlying statement supported the belief" [p. 2], it was hypothesised that articles cite HH92 in a potentially non-neutral way; that is, they may tend to position themselves vis-à-vis the theoretical statement being made explicit within HH92 (that beta-amyloid deposition is the central event in the aetiology of AD). Each citation was therefore classified as "negative" (unconvinced of HH92's ACH's validity) "neutral" (no definitive claim made about the ACH's veracity, or suggesting the need for further evidence before making claims about it) or "positive" (already convinced of the ACH's validity at the time of citing) by Timothy Daly.

Furthermore, since it was recognised that the $\mathrm{ACH}$ as defended within $\mathrm{HH} 92$ is but one version of the $\mathrm{ACH}$, in light of the changes that the field has undergone since $1992[16,7]$, the overall conclusion of the article with respect to the suitably of beta-amyloid as a target as compared to other possible therapeutic strategies was also measured (“ACH conclusion”). This conclusion was typically suggested by the study's results, or found explicitly mentioned in the title, abstract, and/or discussion; it was also classified as negative, neutral, or positive in the same way as HH92 citations.

Thereafter, articles were divided into "Original" and "Review" articles, classified by date, citation rate in Google Scholar (measured as citations per year, to account for articles being published during different years). For each article, the place within the bibliography that HH92 occupied was noted (for articles using a quantified bibliography, 303 articles out of 445). The geography of first-author affiliation was also noted as a function of continent (North America: NA, Europe: EU, Asia: AS, Africa: AF, Australasia, AU). 


\section{$\underline{\text { SAMPLE }}$}

110 original articles within our sample tested the ACH's basic claim. For each article, we obtained the "post-test result" from a semantic analysis of the article's results and discussion section, divided post-test results into "positive," "inconclusive," or "negative." In "inconclusive" articles, we included those articles whose authors, following their test of the $\mathrm{ACH}$, stressed the need for further testing and interpretation before making claims about the ACH's veracity. We then proceeded to test the reproducibility of pro-ACH test results within the sample.

\section{HYPOTHESES}

\section{STATISTICAL ANALYSES}

Data are presented as counts and percentages for categorical variables and as mean \pm standard deviation for normal distribution numerical variables or as median [first quartile $\mathrm{Q}_{0.25}$, third quartile $\mathrm{Q}_{0.75}$ ] for non-normal distribution numerical variables.

Fisher's exact test were performed to compare category distribution of a categorical variable between several groups. Welch's t-test for normal distribution numerical variables or Wilcoxon rank-sum test were performed to compare distribution of a numerical variable between two groups. To compare more than two groups, ANOVA Fisher test or Kruskal-Wallis test were 
performed when appropriate followed by Tukey's HSD test or pairwise Wilcoxon rank-sum tests with Benjamini Hochberg correction for post hoc comparisons.

In order to test the hypothesis that as time passes, HH92 is mentioned earlier in the articles, a one-sided Spearman's rank test between the year of the publication of the articles and their citations per year was performed with rho $<0$ as alternative hypothesis.

\section{HYPOTHESES AND OBJECTIVES: ARTICLE VALENCES}

By measuring citation practices, we hoped to gain information regarding the attitudes of practicing scientists within the $\mathrm{AD}$ field towards the $\mathrm{ACH}$. In this way, positive citations were used as a proxy for acceptance of the authors' belief that beta-amyloid might indeed have some central role to play in $\mathrm{AD}$; neutral citations were seen as a more reserved attitude in need of more compelling evidence; negative citations were seen to represent authors' mistrust of the ACH's basic claim given the available evidence. The various hypotheses we put forward tested the distribution of citation valences, as well as the consequences of citation valence.

\section{INVESTIGATING HARDY ET AL. (2014)'S CLAIM OF ACH DOMINANCE}

We hypothesised that within our sample of articles, given the central place of HH92 in the broader AD literature, there should be a positive majority of both HH92 citations and "pro-ACH" overall article conclusions. 
Furthermore, given the 27-year period over which we measured citation practices, we also measured whether citation valence was associated with three other properties: the article's overall conclusion with respect to the $\mathrm{ACH}$; the Google Scholar citation rate of the citing article itself; and the position of the HH92 within the bibliography of the citing article.

\section{HH92 CITATION AS A PREDICTOR OF ACH VALENCE}

When HH92 is cited positively, we hypothesised that it would result in the author's belief "feeding in" to a pro-ACH overall conclusion, whereas neutral and negative citations would not allow for prediction of overall conclusion based on HH92 citation practice due to confounding factors. This allowed us to measure just how much the HH92 served as a positive influencer of the beliefs of citing authors.

THE IMPACT OF ARTICLE VALENCE ON CITATION RATE OF ARTICLES

We wanted to know if articles citing HH92 favourably, or with a favorable conclusion towards the $\mathrm{ACH}$, were themselves cited more frequently than neutral or negative citers, thus contributing to more "pro-ACH" traffic in the literature, which might explain the success of the $\mathrm{ACH}$ compared to its competitors.

THE EFFECT OF TIME ON THE POSITION OF HH92 CITATION WITHIN THE BIBLIOGRAPHY 
Finally, we wanted to test whether articles citing HH92 favourably cited it earlier on than articles in previous years, as a proxy for measuring how belief in the $\mathrm{AD}$ towards the role of $\beta$-amyloid in AD has evolved since 1992, with the idea of its central role becoming more of a foregone conclusion in such positively-citing papers as a function of time.

\section{SUPPORT FOR THE ACH FROM ORIGINAL ARTICLES}

Given that the $\mathrm{ACH}$ has been dominant, as a necessary scientific condition to justify such dominance, the original articles should provide reproducible support for the $\mathrm{ACH}$ in their post$\mathrm{ACH}$ test results. Within each testing article, we studied the nature of the inference made based on the results from the test (as evidence in favour of the $\mathrm{ACH}$; as inconclusive vis-à-vis the $\mathrm{ACH}$; as evidence against the $\mathrm{ACH}$ ).

\section{RESULTS}

\section{GENERAL CHARACTERISTICS AND FINDINGS}

Of the 445 articles citing HH92 in the sample, 26 (5.8\%) were written between 1992-1999; 97 (21.8\%) between 2000 and 2009, and 322 (77.4\%) between 2010 and 2019. 219 articles (49.2\%) were original research articles and $226(50.8 \%)$ were review articles. Within the 219 original 
research papers, $110(50.7 \%)$ tested the claims of the ACH. 98 (89.1\%) of 110 articles returned a positive test result, suggesting reproducible support for the $\mathrm{ACH}$ from original tests.

The majority $(343,77.1 \%)$ of papers were produced by European and North American research teams, with Asia being the third most productive continent (81, 18.2\%).

\begin{tabular}{|c|c|c|c|c|}
\hline & $\begin{array}{c}\text { all } \\
\mathrm{N}=445\end{array}$ & $\begin{array}{c}\text { original } \\
N=219 \\
(49.21 \%)\end{array}$ & $\begin{array}{c}\text { review } \\
\mathrm{N}=226 \\
(50.79 \%)\end{array}$ & $\mathrm{p}$ \\
\hline Period of publication & & & & 0.471 \\
\hline$[1992-2000[$ & $26(5.84 \%)$ & $13(5.94 \%)$ & $13(5.75 \%)$ & \\
\hline$[2000-2010[$ & $\begin{array}{c}97 \\
(21.80 \%)\end{array}$ & $\begin{array}{c}53 \\
(24.20 \%)\end{array}$ & $\begin{array}{c}44 \\
(19.47 \%)\end{array}$ & \\
\hline$[2010-2019[$ & $\begin{array}{c}322 \\
(72.36 \%)\end{array}$ & $\begin{array}{c}153 \\
(69.86 \%)\end{array}$ & $\begin{array}{c}169 \\
(74.78 \%)\end{array}$ & \\
\hline $\mathrm{ACH}$ tested & $\begin{array}{c}110 \\
(24.83 \%)\end{array}$ & $\begin{array}{c}110 \\
(50.69 \%)\end{array}$ & $0(0.00 \%)$ & $\begin{array}{c}<0.00 \\
1^{*}\end{array}$ \\
\hline \multicolumn{5}{|c|}{ Result of the $\mathrm{ACH}$ test $(\mathrm{MD}=285)$} \\
\hline ACH positive & & $\begin{array}{c}98 \\
(89.09 \%)\end{array}$ & & \\
\hline$A C H$ inconclusive & & $5(4.55 \%)$ & & \\
\hline $\mathrm{ACH}$ negative & & $7(6.36 \%)$ & & \\
\hline $\mathrm{ACH}$ valence & & & & $\begin{array}{c}<0.00 \\
1^{*}\end{array}$ \\
\hline positive & $\begin{array}{c}289 \\
(64.94 \%)\end{array}$ & $\begin{array}{c}169 \\
(77.17 \%)\end{array}$ & $\begin{array}{c}120 \\
(53.10 \%)\end{array}$ & \\
\hline neutral & $\begin{array}{c}109 \\
(24.49 \%)\end{array}$ & $\begin{array}{c}37 \\
(16.89 \%)\end{array}$ & $\begin{array}{c}72 \\
(31.86 \%)\end{array}$ & \\
\hline negative & $\begin{array}{c}47 \\
(10.56 \%)\end{array}$ & $13(5.94 \%)$ & $\begin{array}{c}34 \\
(15.04 \%)\end{array}$ & \\
\hline
\end{tabular}


HH92 valence

0.129

155

positive

neutral

negative

Citation Rate

Geography of 1st author

Asia

Australasia

Europe

North America

Central \& South America

HH92's place in the bibliography $(\mathrm{MD}=142)$
$(34.83 \%)$

276

$(62.02 \%)$

$14(3.15 \%)$

$9.01 \pm$

13.07

81

$(18.20 \%)$

$10(2.25 \%)$

175

(39.33\%)

168

(37.75\%)

$11(2.47 \%)$

$2(0.91 \%)$

9 (3.98\%)
84

(38.36\%)

131

(59.82\%)

$4(1.83 \%)$

$7.75 \pm$

10.89

58

(26.48\%)

2 (0.91\%)

81

(36.99\%)

76

(34.70\%)

92

(40.71\%)
(31.42\%)

145

(64.16\%)

$10(4.42 \%)$

$10.23 \pm$

0.045

14.81

$<0.00$

$1^{*}$ 
Within the entire sample, concerning HH92 citation, 155 (34.8\%) cited HH92 favourably, 276 neutrally (62.0\%), and 14 negatively (3.2\%). Concerning overall $\mathrm{ACH}$ conclusion, 289 articles (64.9\%) had a pro-ACH conclusion, 109 (24.5\%) a neutral conclusion towards the $\mathrm{ACH}, 47$ $(10.6 \%)$ an anti-ACH conclusion. No differences were found between HH92 citation valence according to article types (original/review), geographical origin of first author's affiliation or citation rate, whereas statistical differences were found between $\mathrm{ACH}$ conclusion valence for all these characteristics.

In overall pro-ACH conclusion articles, there were significantly more original articles compared to negative or neutral $\mathrm{ACH}$ conclusion articles $(58.5 \%$ original articles in pro- $\mathrm{ACH}, 33.9 \%$ in neutral and $27.7 \%$ in negative, Cramér's $\mathrm{V}=0.25$, poverall $<0.001$ ); they tended to test the $\mathrm{ACH}$ more than in neutral $\mathrm{ACH}$ conclusion articles $(32.4 \%$ in pro- $\mathrm{ACH}$, vs $8.3 \%(\mathrm{p}<0.001)$ in neutral and vs $17.0 \%$ in negative ( $\mathrm{p}=0.039$ ), Cramér's $\mathrm{V}=0.24$, $\mathrm{p}_{\text {overall }}<0.001$ ); their first author affiliation was more significantly from Asia compared to negative- $\mathrm{ACH}$ (20.8\% for pro-ACH vs $4.3 \%$ for negative- $\mathrm{ACH}$, Cramer's V $=0.19, \mathrm{p}=0.009$ ).

\section{THE ASSOCIATION BETWEEN HH92 CITATION AND ACH VALENCE}

The ACH conclusion of the articles tended to be different according to HH92 citation practice (Cramer's $\mathrm{V}=0.33, \mathrm{p}<0.001$ ). Indeed, the $\mathrm{ACH}$ conclusion was positive in $85.8 \%$ of articles citing HH92 positively, in 55.8\% citing HH92 neutrally and only in 14.3\% citing HH92 negatively. 


\section{HH92 CITATION POSITIVITY AND CITATION RATE OF ARTICLES}

Positively-citing articles had a mean \pm standard deviation citation rate (CR) of $7.8 \pm 10.1$ citations per year; neutral articles had a CR of 9.6 \pm 14.3 ; negatively-citing articles had a CR of $12.0 \pm 16.4$, although these differences were not statistically significant $(p=0.208)$.

Concerning overall ACH conclusion, negative articles had a higher mean CR of 13.6 \pm 15.7 , neutral $10.1 \pm 17.6$, and positive $7.9 \pm 10.1$. Negative articles had a significantly higher CR than positive-ACH articles (Cliff's delta $=-0.25, \mathrm{p}=0.007$ ).

\section{CHANGES IN HH92'S PLACE WITHIN THE BIBLIOGRAPHY WITHIN POSITIVELY-CITING ARTICLES}

$303(68.1 \%)$ articles had a numerical bibliography, which we used to measure the place of the HH92 within the bibliography. These articles were not a perfect representation of the greater sample, principally since they tended to cite HH92 more positively than the articles with nonnumerical bibliography $(37.6 \%$ v $28.9 \%, \mathrm{p}=0.040$ and Cramer's $\mathrm{V}=0.12)$.

We found no association between the year of publication and HH92's place in the bibliography for the entire sample ( $r h o=-0.05, \mathrm{p}=0.371)$, but when looking at articles citing HH92 positively, we found an association between place in the bibliography as a function of decade (rho=-0.19, $\mathrm{p}=0.020)$ whereas there was no association on articles citing HH92 neutrally $(\mathrm{rho}=0.03, \mathrm{p}=0.670)$ 
[Figure 2]. Only 6 articles cited HH92 negatively so we did not calculate the Spearman correlation coefficient.
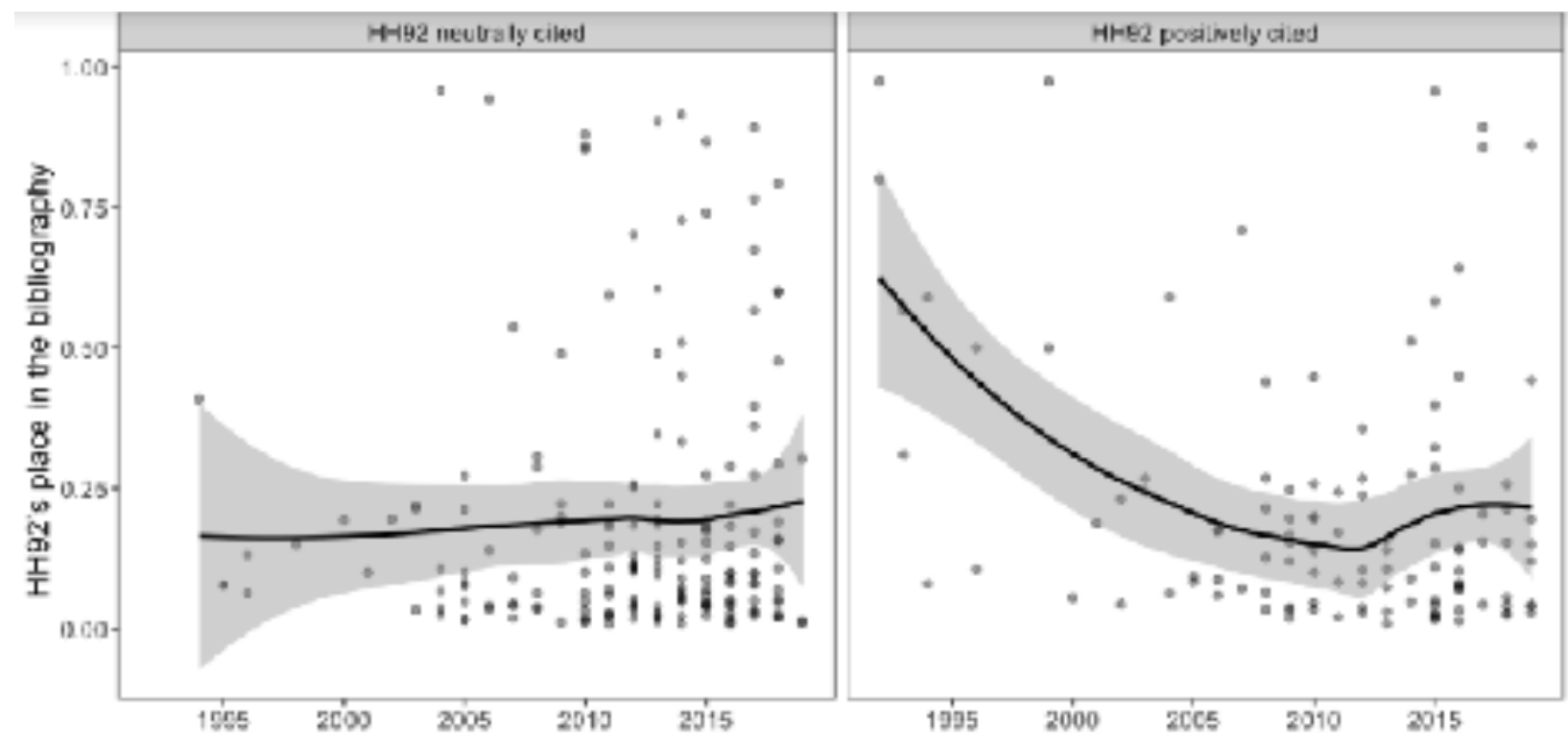

Figure 2: The identification of two major trends within citing articles: neutral attitudes were consistent between 1992 and 2019; the group of articles citing HH92 positively had a tendance to cite it earlier in the paper in latter years, taking it as an established authority.

\section{DISCUSSION}

The results of this bibliometric study support neither "herd-like behaviour" [17] nor Hunter et al.'s claim of the existence of "two broad groups"[18] for and against the ACH, for at least three reasons. Firstly, the majority of authors encountering the idea that beta-amyloid has some central role to play in AD do not cite HH92 positively. Secondly, the majority is actually made up of "neutral" citing authors. Thirdly, any negative citations or anti-ACH traffic were in a small 
minority, and thus such "anti-ACH" opinions are not in a "broad group." In summary, the large amount of "pro-ACH" conclusions and traffic in this network of articles cannot be explained by a bias towards the positivity of HH92 citation practices.

We identified two major trends within citing behaviour: a group of articles citing HH92 positively and tending towards taking it as an established authority with time, versus an unchanging majority of articles with a neutral attitude towards HH92. Negative HH92 citations were exceedingly rare, and anti-ACH traffic in the network represents a $10.6 \%$ minority. We did not encounter "herd-like" behaviour: those original articles testing the ACH found an overwhelming majority $(89 \%)$ of pro-ACH test results (thus justifying their pro-ACH conclusion), and there was no majority of positive HH92 citations or pro-ACH conclusions in review articles. Further studies with actual citation networks, as opposed to individual articles, could shed greater light on the question of the potential "herd-like" behavior of the AD field.

Hardy et al. [1]'s claim that the $\mathrm{ACH}$ has dominated opinion appears true given the majority (67.4\%) of pro-ACH conclusions. HH92 can only accurately predict $\mathrm{ACH}$ conclusion when HH92 citation is positive (in $86.8 \%$ of cases). However, positive HH92 citation did not have a favorable effect on $\mathrm{CR}$, but rather a tendency towards the opposite effect. If anything, our results suggest that coming to an anti-ACH conclusion is a more favourable way of achieving a higher CR.

The results suggested here do not suggest that one scientific paper can fully "fix belief" in an authoritative manner in a community of researchers. It is clear that ideas around beta-amyloid's 
central role in $\mathrm{AD}$ have remained alive in the literature, but the theoretical changes the $\mathrm{ACH}$ has undergone have clearly been taken into account by the community.

Furthermore, the empirical support we identified for the ACH was overwhelmingly positive, in terms of the amount of empirical studies with a pro-ACH test result in our sample. In further studies, we will discuss the limits of reproduction as a model of confirmation of a hypothesis, and discuss the idea of the "triangulation" of "different lines of evidence" from different methods [19].

This paper is not the first bibliometric study of the AD field [20, 21]. However, previously study have focused on trends, and ours is the first to test hypotheses about the reception of an idea as the central focus of the paper. Furthermore, placing this paper within the context of the intellectual space occupied by the $\mathrm{ACH}$, it is the first time-to the best of our knowledge-that a hypothesis made outside the scientific AD literature (Lovestone's claim that "Our failing in the Alzheimer's field is to have acted like a herd" in a Financial Times article) has been tested by an article within it. Indeed, although the $\mathrm{ACH}$ is the object of intense debate within the scientific literature, outside the strict publishing norms of published science such as journalistic interviews, scientists have their say on efforts within the field. Recognising that the scientific literature does not give absolute transparency with regards to scientists' intuitions about research, our group will also publish results from an anonymous, international survey in collaboration with the Alzheimer's Association with scientists and clinicians to have direct access to their opinions on 
the $\mathrm{ACH}$ and other theories and treatments of $\mathrm{AD}$ without having to pass through the filter of the literature.

Concerning the limitations of the present study, we were well aware when we started this work that GA Higgins, co-author of HH92, is a discredited researcher. The retraction of Kawabata et al. [22] in which he appeared to have exaggerated the extent of neuronal degeneration in a transgenic mouse model of AD overexpressing APP was rightly seen as a scandal. However, we consider the fact that pro-ACH ideas have survived until 2020 in spite of such unfavourable coverage as a testament to the wide evidence base in favour of them.

Furthermore, we recognise that the number of articles (445) in our sample represents a drop in the ocean of the 35,000 papers studying beta-amyloid in AD. However, defense of the ACH represents a broad church-there is no one amyloid hypothesis-and there are various ways in which authors might defend the $\mathrm{ACH}$ alone or integrate it into more complex aetiologies. There is no denying that comparative studies between the fates of the ideas in this hub and those in others would enrich the empirical study of the ACH's place within the literature. One can see our manuscript as a first attempt to grasp the epistemology of the $\mathrm{ACH}$ in the vast field of Alzheimer's disease research. Confirmatory studies, including natural language processing analyses of the literature would certainly be important before drawing definitive conclusions about citation practices within the ACH field, but we feel they are outside of the scope of this manuscript. 
Finally, beyond the problem of sample size, the fact that the majority of citations were neutral suggests that nuances within this heterogenous community of researchers are real but not wellcaptured by Greenberg's (2009) methodology. For example, scholars in philosophy of science[23] have previously distinguished between a scientist accepting a theory as a basis for action (i.e. testing its claims and comparing it to other theories within the field in review articles) versus believing it to be factually true. It is not obvious that the citation polarity used herein allows us to distinguish between these subtleties and further studies could conduct further linguistic analyses to distinguish between such nuances. Furthermore, although the classic distinction between "original" and "review" articles allows us to divide articles in a simple way, there are different kinds of reviews, such as classical "narrative" reviews, meta-analyses, etc., and the lack of distinction between these groups risks glossing over important nuances between article types.

In conclusion, we consider that this objective, empirical study of citation practices and support for the $\mathrm{ACH}$ suggests that the $\mathrm{ACH}$ has indeed been dominant in the field, has quantitatively good empirical suggest but that there are no problematic citation practices or herd-like behaviour identified. Further studies, using more nuanced measures of scientific belief, as well as more elaborate models of scientific confirmation, could provide further insight into the acceptance of the $\mathrm{ACH}$ by the scientific community as well as suggesting ideas on how to improve the ACH's robustness.

\section{ACKNOWLEDGEMENTS}


Thanks to Hervé Maisonneuve for showing the Greenberg (2009) paper to Timothy Daly, and to Mathieu Bourdenx for his helpful comments on the manuscript.

\section{CONFLICTS OF INTEREST}

The authors declare no conflicts of interest.

\section{BIBLIOGRAPHY}

1. J. Hardy et al., Pathways to Alzheimer's disease. J Intern Med 275, 296-303 (2014).

2. P. P. Liu, Y. Xie, X. Y. Meng, J. S. Kang, History and progress of hypotheses and clinical trials for Alzheimer's disease. Signal Transduct Target Ther 4, 29 (2019).

3. S. Budd Haeberlein et al., Clinical Development of Aducanumab, an Anti$A \beta$ Human Monoclonal Antibody Being Investigated for the Treatment of Early Alzheimer's Disease. J Prev Alzheimers Dis 4, 255-263 (2017).

4. K. Herrup, The case for rejecting the amyloid cascade hypothesis. Nature Neuroscience 18, 794-799 (2015).

5. A. Abbott, E. Dolgin, Failed Alzheimer's trial does not kill leading theory of disease. Nature 540, 15-16 (2016).

6. P. A. Schilp. The Philosophy of Karl Popper. 2 volumes. La Salle, III: Open Court.

7. D. J. Selkoe, J. Hardy, The amyloid hypothesis of Alzheimer's disease at 25 years. EMBO Mol Med 8, 595-608 (2016).

8. C.S. Peirce. Popular Science Monthly 12 (November 1877), pp. 1-15.

9. J. Joseph et al., Copernicus revisited: amyloid beta in Alzheimer's disease. Neurobiol Aging 22, 131-146 (2001).

10. A. Mudher, S. Lovestone, Alzheimer's disease-do tauists and baptists finally shake hands? Trends Neurosci 25, 22-26 (2002).

11. S. A. Greenberg, How citation distortions create unfounded authority: analysis of a citation network. BMJ 339, b2680 (2009). 
12. J. Hardy, D. Allsop, Amyloid deposition as the central event in the aetiology of Alzheimer's disease. Trends Pharmacol Sci 12, 383-388 (1991).

13. K. Beyreuther, C. L. Masters, Amyloid precursor protein (APP) and beta A4 amyloid in the etiology of Alzheimer's disease: precursor-product relationships in the derangement of neuronal function. Brain Pathol 1, 241-251 (1991).

14. J. A. Hardy, G. A. Higgins, Alzheimer's disease: the amyloid cascade hypothesis. Science 256, 184-185 (1992).

15. D. J. Selkoe, The molecular pathology of Alzheimer's disease. Neuron 6, 487-498 (1991).

16. J. Hardy, D. J. Selkoe, The amyloid hypothesis of Alzheimer's disease: progress and problems on the road to therapeutics. Science 297, 353-356 (2002).

17. S. Lovestone in C. Cookson, in Financial Times. (http://www.ft.com/ content/845aeb0a-ced7-11e7-b781-794ce08b24dc, 2017). Accessed 12-2019.

18. S. Hunter, R. P. Friedland, C. Brayne, Time for a change in the research paradigm for Alzheimer's disease: the value of a chaotic matrix modeling approach. CNS Neurosci Ther 16, 254-262 (2010).

19. M. R. Munafò, G. Davey Smith, Robust research needs many lines of evidence. Nature 553, 399-401 (2018).

20. A. Serrano-Pozo, G. M. Aldridge, Q. Zhang, Four Decades of Research in Alzheimer's Disease (1975-2014): A Bibliometric and Scientometric Analysis. J Alzheimers Dis 59, 763-783 (2017).

21. R. Dong, H. Wang, J. Ye, M. Wang, Y. Bi, Publication Trends for Alzheimer's Disease Worldwide and in China: A 30-Year Bibliometric Analysis. Front Hum Neurosci 13, 259 (2019).

22. S. Kawabata, G. A. Higgins, J. W. Gordon, Alzheimer's retraction. Nature 356, 23 (1992).

23. B. van Fraassen, The Scientific Image. (Oxford University Press, U.S.A., 1980). 